\title{
Improved Catalytic Transfer Hydrogenation of levulinate esters with alcohols over $\mathrm{ZrO}_{2}$ catalyst ${ }^{\dagger}$
}

\author{
Tommaso Tabanelli,,$^{1, *}$ Paola Blair Vásquez, ${ }^{1}$ Emilia Paone, ${ }^{2}$ Rosario Pietropaolo, ${ }^{2}$ Nikolaos \\ Dimitratos, ${ }^{1}$ Fabrizio Cavani, ${ }^{1}$ Francesco Mauriello ${ }^{2}$ \\ 1 Dipartimento di Chimica Industriale “Toso Montanari”, Università di Bologna, Via Risorgimento 4, 40136 \\ Bologna, Italy \\ 2 Dipartimento DICEAM, Università Mediterranea di Reggio Calabria, Loc. Feo di Vito, I-89122 Reggio \\ Calabria, Italy \\ * Correspondence: tommaso.tabanelli@unibo.it; Tel.: 00390512093861 \\ + Presented at the 6th International Electronic Conference on Sensors and Applications, \\ 15-30 November 2019; Available online: https://ecsa-6.sciforum.net/
}

Published: 14 November 2019

\begin{abstract}
Levulinic acid (LA) and its esters (alkyl levulinates) are polyfunctional molecules that can be obtained from lignocellulosic biomass. Herein, the catalytic conversion of methyl and ethyl levulinates into $\gamma$-valerolactone (GVL) via catalytic transfer hydrogenation (CTH) by using methanol, ethanol, and 2-propanol as the H-donor/solvent, was investigated under both batch and gas-flow conditions. In particular, high-surface-area, tetragonal zirconia has proven to be a suitable catalyst for this reaction. 2-propanol was found to be the best H-donor under batch conditions, with ethyl levulinate giving the highest yield in GVL. However, long reaction times and high autogenic pressures are needed in order to work in the liquid phase at high temperature with light alcohols. The reactions occurring under continuous gas-flow conditions, at atmospheric pressure and relatively low contact time (1 s), were found to be much more efficient, also showing excellent GVL yields when EtOH was used as the reducing agent (GVL yield of around 70\% under optimized conditions). The reaction has been tested also using a true bio-ethanol, derived from agricultural waste. These results represent the very first examples of the CTH of LE under continuous gas-flow conditions reported in the literature.
\end{abstract}

Keywords: zirconia; catalytic transfer hydrogenation (CTH), alkyl levulinates, ethanol, propanol, continuous-flow processes.

\section{Introduction}

The increased needs to promote a sustainable industrial development has led to the search of alternatives and renewable raw materials and feedstocks for our productions. One of the most promising alternatives to petrochemistry are biorefineries based on lignocellulosic biomass valorization. Lignocellulose is composed of three main component and bio-polymers, namely lignin, hemicellulose, and cellulose from which a wide plethora of valuable bio-platform molecules can be obtained [1,2]. Among them, levulinic acid (LA) can be obtained from cellulose through a multi-step sequence of reactions in which hydrolysis of the bio-polymer is followed by dehydration and hydration reactions to yield the target product and formic acid [3]. With both a ketonic and carboxylic function group, LA is a molecule of great interest and with a great versatility. In particular, LA has been studied and used for the synthesis of various value-added chemicals (namely tetrahydrofuran, $\gamma$-valerolactone (GVL), angelica lactones (AL), 1,4-pentanediol (1,4-PDO), among others) [4]. For all of these reasons, its production has increased from 450,000 kg/year (in the 1990s), to around 3800 
tons/year in 2020 [3]. It is therefore not surprising that the United States Department of energy has classified LA as one of the top twelve most promising bio-based building block chemicals [5].

Nowadays, the most applied strategy in LA valorization is through reduction by means of catalytic hydrogenation with molecular hydrogen $\left(\mathrm{H}_{2}\right)$ in gas and liquid phase. Some studies show the catalytic transformation of LA and its esters using homogeneous catalysts [6,7]. However, this approach is not attractive given the complexity for catalyst separation and recovery [8]. Therefore, the use of heterogeneous catalysts has been investigated the last 10 years. It has been reported the use of catalysts containing noble metal nanoparticles supported on high surface area materials, which have allowed to reach complete conversions and high selectivity to GVL (98-99\%) [9]. However, noble-metal catalysts are expensive and harsh conditions (high hydrogen pressure and reaction temperature) are still required to achieve satisfying yield and selectivity toward the target products [9-11]. In addition, most of the published studies still depend on $\mathrm{H}_{2}$ as reducing agent. This rends the process less sustainable since, through an energetically intensive procedure (e.g. methane steam reforming), fossil fuels are still the main feedstock for hydrogen production [12-13]. A suitable and sustainable alternative, is represented by the catalytic transfer hydrogenation (CTH) using the Meerwein-Ponndorf-Verley (MPV) mechanism. This approach uses organic molecules, such as alcohols, that behave as hydrogen donors toward a carbonyl group in the presence of a catalyst containing both acid and base Lewis sites $[7,9,14]$. Secondary alcohols, such as isopropanol, are more suitable for the chemical process, since the proposed reaction mechanism has shown a greater stability of the secondary carbocation formed as an intermediate during the reaction [15].

Typically, noble-metal catalysts have been used for the CTH of LA. In particular, the use of supported $\mathrm{Ru}$ with isopropanol as the preferred H-donor has led to achieve yields above $80 \%$ for GVL working on the liquid phase and using alkyl levulinates as the main substrates [16,17]. In addition, Raney Ni has led to yields of up to $99 \%$ for GVL while working with mild conditions (room temperature- $80^{\circ} \mathrm{C}$ ), however with the use of an excess of isopropanol [17].

Since CTH through the MVP mechanism is achieved while in the presence of a catalyst containing Lewis acid/base pairs, several studies have focused on the use of $\mathrm{ZrO}_{2}$ for the CTH of LA and its esters [18]. Indeed, $\mathrm{ZrO}_{2}$ has been found to be a suitable catalyst for the target reaction due to its amphoteric character. This allows the simultaneous activation of both the carbonyl group of LA and the alcohol on the actives sites of the support $[18,19]$. Also for this reason, modified- $\mathrm{ZrO}_{2}$ (e.g. $\mathrm{Zr}$-Al mixed oxides), were tested for the liquid-phase (batch configuration) $\mathrm{CTH}$ of ethyl levulinate (EL) using different alcohols as H-donors: methanol, ethanol, 1- and 2-propanols, and cyclohexanol. As expected, isopropanol gave the highest selectivity for GVL (83-84\%) at 95\% of EL conversion [20].

Even though isopropanol seems to be a great H-donor, it is known that secondary alcohols are likely to form their corresponding ketones which may favor unwanted side reactions (e.g. aldolic condensations). Therefore, simpler molecules such as methanol and ethanol have become attractive alternatives $[7,15,21]$. However, mechanistic studies have shown that primary alcohols are less available to undergo hydride shift [22]. Nevertheless, ethanol represents an interesting alternative given its high abundance, non-toxicity, sustainability, environmentally benign nature and finally it can be obtained through fermentation of biomasses [17, 23].

At the moment, most of the published studies for the CTH of LA and its esters using $\mathrm{ZrO}_{2}$ based catalyst have been performed in the liquid phase using batch reactors and isopropanol as $\mathrm{H}$-donor. Furthermore, levulinate esters are characterized by a lower boiling points compared to LA and can be directly obtained by the acid-catalyzed alcoholysis of cellulose-derived carbohydrates. In this way the needs of an additional esterification step of LA is avoided, and finally the sustainability of their direct utilization as raw material is increased significantly [24].

For all these reasons, we decided to investigate the CTH of levulinate ester using a synthesized high specific surface area tetragonal zirconia catalyst in a gas-phase continuous-flow, fixed-bed reactor. In particular, we investigated systematically/thoroughly the effects of different parameters (contact time, reaction temperature, the type of alcohol used as $\mathrm{H}$-donor and the effect of the leaving group of the levulinate ester) as well as the study of reaction and catalyst's deactivation mechanism [25]. The results obtained in the gas-phase were also carefully compared to the ones obtainable in 
liquid phase and batch conditions [26]. Herein the most interesting results are summarized and highlighted.

\section{Materials and Method}

Reagents and standards were analytical grade, all supplied by Sigma-Aldrich (Merk) and used as received. A real mixture of bio-ethanol (derived from molasses and cereal fermentation) was provided by Caviro, a leading wine Italian producer group. Bio-ethanol volumetric composition was: ethanol $95 \%$, acetic acid $1.3 \%$, ethyl acetate $1.2 \%$, methanol $1.8 \%$, aldehydes and acetals $0.7 \%$.

For all the details related to catalyst preparation and characterization refer to ref. [25].

For all the details related to both the continuous-flow gas-phase reactor and the liquid phase autoclave reactor and catalytic tests procedures please refer to ref. [25] and [26].

\section{Results and discussion}

Firstly, the effect of the reaction temperature on the feasibility of the methyl levulinate (ML) reduction to GVL using ethanol as $\mathrm{H}$-donor has been investigated in the gas-phase over $\mathrm{ZrO}_{2}$ (Figure 1). Interestingly, in our reaction conditions (see Figure 1 caption), ML conversion was complete also at the lowest temperature, while GVL was formed only between 200 and $300^{\circ} \mathrm{C}$ with a maximum yield of $65 \%$ at $250^{\circ} \mathrm{C}$. In addition, the carbon balance of the reaction follow a volcano plot with a maximum of $90 \%$ at $250^{\circ} \mathrm{C}$. For all these reasons, $250^{\circ} \mathrm{C}$ was selected as best reaction conditions for the following tests.

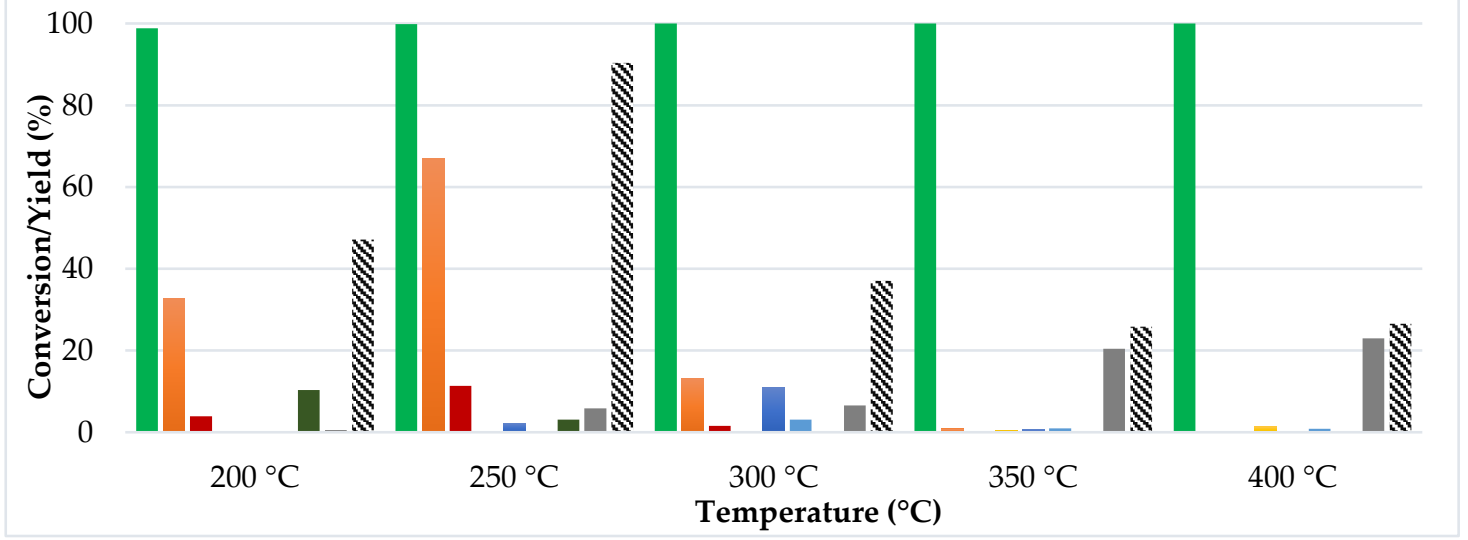

Figure 1. $\mathrm{CTH}$ of $\mathrm{ML}$ with ethanol as $\mathrm{H}$-donor over $\mathrm{ZrO}_{2}$. Reaction conditions: $\mathrm{ML}: \mathrm{EtOH}=1: 10$ (molar ratio), $\tau=$

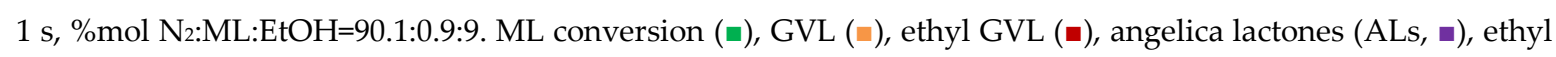
pentenoate $(\square)$, ethyl pentanoate $(\square)$, ethyl levulinate $(E L, \square)$, other $(\square)$, carbon balance (black, striped).

In this way, we performed a comprehensive investigation of the effect of the alcohols used as $\mathrm{H}$ donor in the CTH of ML in both gas-phase, (continuous-flow reactor), and liquid phase (batch, autoclave reactor) conditions. From an overview of the obtained results (Figure 2) few important points can be highlighted:

- the superior activity (higher ML conversion) and yield to GVL obtained in the gas-phase continuous flow conditions compared to the liquid phase, regardless the alcohol used as $\mathrm{H}$ donor;

- the very poor results obtained using methanol as $\mathrm{H}$-donor for the target reaction in terms of desired yield of products. Further investigations by using ethyl levulinate (EL) as the chosen substrate have proved the preferential tendency of methanol to promote both trans-esterification and alcoholysis of the intermediates (angelica lactones) reactions;

- isopropanol has been confirmed as the best H-donor for the liquid phase conditions while, in the continuous-flow system in the gas-phase conditions, ethanol and isopropanol have led to very similar results with complete conversion of ML (at least for six hours of reaction) and very good GVL yield (from 60 to $80 \%$ ); 
- performing the catalytic tests using EL as substrate (instead of ML), using the same reaction conditions as shown in Figure 2, a slight improvement of the obtained results in terms of catalytic activity and GVL yield have been observed. This phenomenon may be attributed, to a limited extent, to an increased efficiency of $\mathrm{EtOH}$ as the leaving group in the intramolecular cyclization of EL to angelica lactones [26].
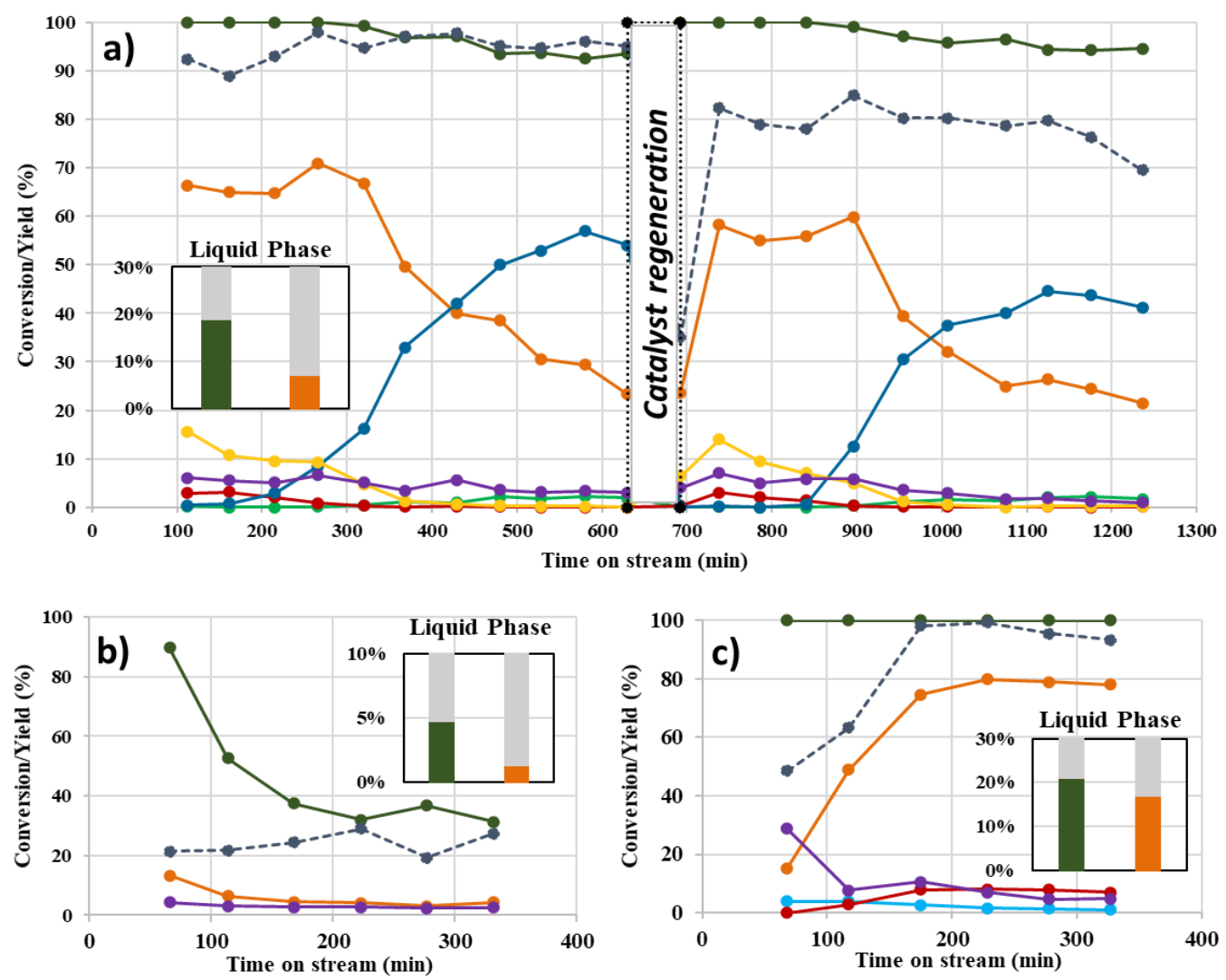

Figure 2. $\mathrm{CTH}$ of $\mathrm{ML}$ with different $\mathrm{H}$-donor over $\mathrm{ZrO}_{2}$ : a) Ethanol; b) Methanol; c) isopropanol. Reaction conditions for the gas phase (scatter charts): ML:Alcohol=1:10 (molar ratio), $\tau=1 \mathrm{~s}, \% \mathrm{~mol}$ $\mathrm{N}_{2}$ :ML:Alcohol=90.1:0.9:9. Reaction conditions for the liquid phase (histograms): $40 \mathrm{~mL}$ solution of ML or EL (10 wt \%), $\mathrm{T}: 250{ }^{\circ} \mathrm{C}, 0.30 \mathrm{~g}$ of $\mathrm{ZrO}_{2}$ catalyst, reaction time $8 \mathrm{~h}, \mathrm{~N}_{2}$ pressure 10 bar, stirring $500 \mathrm{rpm}$. ML conversion (dark green), GVL (orange), ethyl GVL (yellow), angelica lactones (light green), ethyl pentenoate (red), ethyl levulinate (EL, blue), other (purple), carbon balance (dashed line).

However, in the long-term stability tests performed with ethanol (Figure 2a), the progressive continuous deposition of heavy carbonaceous compounds over the catalytic surface, have led to the blockage and poisoning of the active Lewis acid sites, and therefore have led to a progressive decrease of conversion and change in the chemo-selectivity, promoting the alcoholysis of angelica lactones back to EL. Nevertheless, the in situ regeneration of the catalyst was achieved successfully, by performing a heat treatment, by feeding air at $400{ }^{\circ} \mathrm{C}$ for $2 \mathrm{~h}$ and allowed an almost complete recovery of the initial catalytic behavior, proving that the deactivation of $\mathrm{ZrO}_{2}$ is reversible and regeneration could be achieved in a simple and practical manner.

Finally, a real bio-ethanol mixture was used as H-donor for ML at the previously optimized conditions. Figure 3 shows that bio-ethanol gave a slightly less satisfactory catalytic performance compared to the one obtained with HPLC-grade ethanol. This is probably due to the presence of impurities on bioethanol (i.e. acetic acid and aldehydes) that could foster the formation of heavy carbonaceous compounds on the catalytic surface, promoting a faster deactivation of the catalyst and in this way decreasing the maximum obtainable GVL yield. 


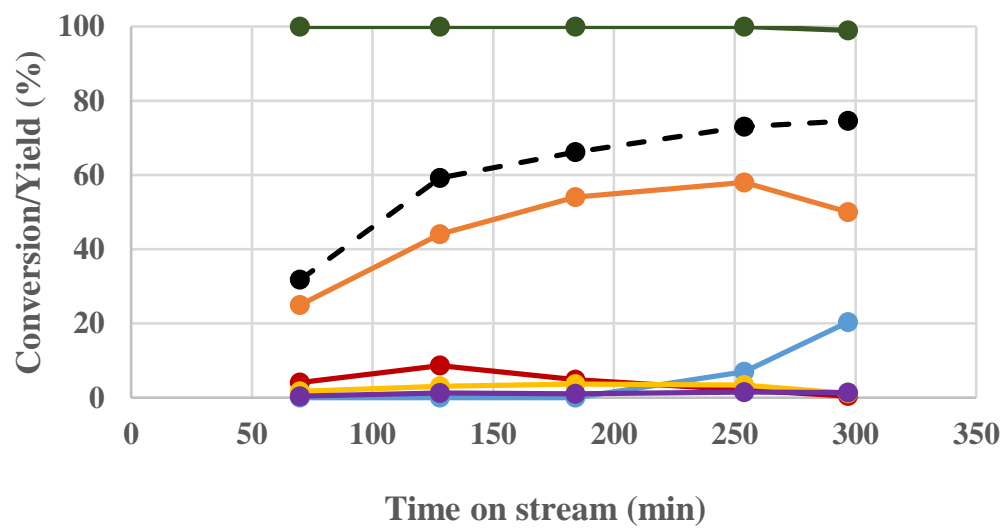

Figure 3. $\mathrm{CTH}$ of $\mathrm{ML}$ with a real bio-ethanol mixture as $\mathrm{H}$-donor over $\mathrm{ZrO}_{2}$.Reaction conditions: ML:bioethanol=1:10 (molar ratio), $\tau=1 \mathrm{~s}, \%$ mol N2:ML:bio-ethanol=90.1:0.9:9. ML conversion (dark green), GVL (orange), ethyl GVL (yellow), angelica lactones (light green), ethyl pentenoate (red), ethyl levulinate (EL, blue), other (purple), carbon balance (dashed line).

\section{Conclusions}

The CTH of alkyl levulinates with a range of alcohols over heterogeneous zirconia catalyst showed a superior catalytic behavior when the reaction is performed in a fixed-bed, continuous flow system in the gas phase. In particular, high surface tetragonal $\mathrm{ZrO}_{2}$ is a suitable catalyst for the target reaction due to its ability to activate both the substrate and the alcohol over Lewis acid and basic sites. During the first 300 minutes of reaction, under the optimized conditions, a full conversion was achieved, and the reaction was selective towards the formation of GVL. At longer reaction times on stream, the deposition of heavy carbonaceous compounds over the active sites was observed. In this way deactivation of the catalyst and in addition a change in the chemo-selectivity of the reaction was observed (e.g. alcoholysis of angelica lactones to yield EL). The latter effect was observed in all the catalytic tests performed in the gas-phase regardless the type of alkyl levulinate nor the chemical nature of the alcohol used. Moreover, the in situ regeneration of the catalyst was achieved when exposing it to a flow of air at $400{ }^{\circ} \mathrm{C}$ for $2 \mathrm{~h}$, restoring its initial catalytic behavior. On the other hand, $\mathrm{ZrO}_{2}$ was not able to activate methanol as $\mathrm{H}$-donor, achieving low conversion of ML and low amounts of GVL. Isopropanol was proven to be an excellent $\mathrm{H}$-donor, allowing complete conversion for ML and high yield of GVL. Nevertheless, when ethanol (and bio-ethanol) was used as H-donor, a similar catalytic behavior was observed in this way opening new possibilities toward a sustainable route to GVL production.

Author Contributions: Gas-phase catalytic tests, catalysts characterization and data analysis, T.T.; Gas-phase catalytic tests, catalyst preparation, P.B.V.; Liquid phase catalytic tests and data analysis, E.P., R.P. and F. M.; writing and manuscript editing N.D. and F.C.

Acknowledgments: We gratefully acknowledge the financial support received from SINCHEM Grant to carry out this work. SINCHEM is a Joint Doctorate program selected under the Erasmus Mundus Action 1 (framework agreement no. 2013-0037) of the European Union.

Conflicts of Interest: "The authors declare no conflict of interest."

\section{References}

1. Ghosh, D.; Dasgupta, D.; Agrawal, D.; Kaul, S.; Adhikari, D. K.; Kurmi, A. K.; Arya, P. K.; Bangwal, D.; Negi, M. S. Fuels and Chemicals from Lignocellulosic Biomass: An Integrated Biorefinery Approach. Energy and Fuels, 2015, 29 (5), 3149-3157.

2. Wettstein, S. G., Martin Alonso, D., Gürbüz, E. I. \& Dumesic, J. A. Roadmap for Conversion of Lignocellulosic Biomass to Chemicals and Fuels. Curr. Opin. Chem. Eng. 2012, 1, 218-224.

3. Mukherjee, A., Dumont, M-J., Raghavan, V. Review: Sustainable production of hydroxymethylfurfural and levulinic acid: Challenges and opportunities. Biomass and Bioenergy, 2015, 72, 143-183. 
4. Rackemann, D. W. \& Doherty, W. O. The conversion of lignocellulosics to levulinic acid. Biofuels, Bioprod. Biorefining, 2011, 5, 198-214.

5. Werpy, T. \& Petersen, G. Top Value Added Chemicals from Biomass Volume I - Results of Screening for Potential Candidates from Sugars and Synthesis Gas. U.S. Dep. Energy (2004) doi:10.2172/15008859.

6. Omoruyi, U., Page, S., Hallett, J. \& Miller, P. W. Homogeneous Catalyzed Reactions of Levulinic Acid: To $\gamma$-Valerolactone and Beyond. ChemSusChem, 2016, 9, 2037-2047.

7. Gilkey, M. J. \& Xu, B. Heterogeneous Catalytic Transfer Hydrogenation as an Effective Pathway in Biomass Upgrading. ACS Catal. 2016, 6, 1420-1436.

8. Horváth, I. T., Mehdi, H., Fábos, V., Boda, L. \& Mika, L. T. $\gamma$-Valerolactone a sustainable liquid for energy and carbon-based chemicals. Green Chem., 2008, 10, 238-242.

9. Upare, P. P.; Lee, J. M.; Hwang, D. W.; Halligudi, S. B.; Hwang, Y. K.; Chang, J. S. Selective Hydrogenation of Levulinic Acid to $\gamma$-Valerolactone over Carbon-Supported Noble Metal Catalysts. J. Ind. Eng. Chem. 2011, 17 (2), 287-292.

10. Yan, Z.; Lin, L.; Liu, S. Synthesis of Gamma -Valerolactone by Hydrogenation of Biomass-Derived Levulinic Acid over Ru/C Catalyst. Energy Fuels 2009, 23 (8), 3853-3858.

11. Sudhakar, M, Kumar, V. V., Naresh. G., Lakshmi Kantam, M., Bhargava, S. K. Vapor phase hydrogenation of aqueous levulinic acid over hydroxyapatite supported metal $(\mathrm{M}=\mathrm{Pd}, \mathrm{Pt}, \mathrm{Ru}, \mathrm{Cu}, \mathrm{Ni})$ catalysts. Appl. Catal. B Environ., 2016, 180, 113-120.

12. Boddien, A.; Loges, B.; Junge, H.; Beller, M. Hydrogen Generation at Ambient Conditions: Application in Fuel Cells. ChemSusChem, 2008, 1 (8-9), 751-758.

13. Holladay, J. D.; Hu, J.; King, D. L.; Wang, Y. An Overview of Hydrogen Production Technologies. Catal. Today, 2009, 139 (4), 244-260.

14. Kuwahara, Y., Kaburagi, W., Osada, Y., Fujitani, T. and Yamashita, H. Catalytic transfer hydrogenation of biomass-derived levulinic acid and its esters to gamma-valerolactone over $\mathrm{ZrO}_{2}$ catalyst supported on SBA15 silica. Catal. Today, 2017, 281, 418-428.

15. Scholz, D.; Aellig, C.; Hermans, I. Catalytic Transfer Hydrogenation/ Hydrogenolysis for Reductive Upgrading of Furfural and 5-(Hydroxymethyl)Furfural. ChemSusChem 2014, 7 (1), 268-275.

16. Kuwahara, Y.; Kaburagi, W.; Fujitani, T. Catalytic Transfer Hydrogenation of Levulinate Esters to $\gamma$ Valerolactone over Supported Ruthenium Hydroxide Catalysts. RSC Adv. 2014, 4 (86), 45848-45855.

17. Yang, Z.; Huang, Y.-B.; Guo, Q.-X.; Fu, Y. RANEY® Ni Catalyzed Transfer Hydrogenation of Levulinate Esters to $\gamma$-Valerolactone at Room Temperature. Chem. Commun. 2013, 49 (46), 5328.

18. Komanoya, T.; Nakajima, K.; Kitano, M.; Hara, M. Synergistic Catalysis by Lewis Acid and Base Sites on ZrO2 for Meerwein-Ponndorf-Verley Reduction. J. Phys. Chem. C., 2015, 119 (47), 26540-26546.

19. Zhu, Y., Liu, S., Jaenicke, S. \& Chuah, G. Zirconia catalysts in Meerwein-Ponndorf-Verley reduction of citral. Catal. Today, 2004, 97, 249-255.

20. He, J.; Li, H.; Lu, Y.; Liu, Y.; Wu, Z.; Hu, D.; Yang, S. Cascade Catalytic Transfer Hydrogenation Cyclization of Ethyl Levulinate to Valerolactone with $\mathrm{Al}$ - Zr Mixed Oxides. Appl. Catal. A, 2016, 510, 11-19.

21. Grazia, L.; Lolli, A.; Folco, F.; Zhang, Y.; Albonetti, S.; Cavani, F. Gas-Phase Cascade Upgrading of Furfural to 2-Methylfuran Using Methanol as a H-Transfer Reactant and MgO Based Catalysts. Catal. Sci. Technol. 2016, 6 (12), 4418-4427.

22. Gliński, M.; Ulkowska, U. Reactivity of Alcohols in Chemoselective Transfer Hydrogenation of Acrolein over Magnesium Oxide as the Catalyst. Catal. Lett. 2011, 141 (2), 293-299.

23. Chia, M.; Dumesic, J. A. Liquid-Phase Catalytic Transfer Hydrogenation and Cyclization of Levulinic Acid and Its Esters to $\gamma$-Valerolactone over Metal Oxide Catalysts. Chem. Commun. 2011, 47 (44), 12233.

24. Neves, P.; Antunes, M. M.; Russo, P. A.; Abrantes, J. P.; Lima, S.; Fernandes, A.; Pillinger, M.; Rocha, S. M.; Ribeiro, M. F.; Valente, A. A. Production of Biomass-Derived Furanic Ethers and Levulinate Esters Using Heterogeneous Acid Catalysts. Green Chem. 2013, 15 (12), 3367.

25. Tabanelli, T., Paone, E., Vásquez, P. B., Pietropaolo, R., Cavani, F., and Mauriello F. Transfer Hydrogenation of Methyl and Ethyl Levulinate Promoted by a $\mathrm{ZrO}_{2}$ Catalyst: Comparison of Batch vs Continuous GasFlow Conditions. ACS Sustain. Chem. Eng. 2019, 7, 9937-9947.

26. Vásquez, P. B., Tabanelli, T., Monti, E., Albonetti, S., Bonincontro, D., Dimitratos, N. and Cavani F. GasPhase Catalytic Transfer Hydrogenation of Methyl Levulinate with Ethanol over ZrOz. ACS Sustain. Chem. Eng. 2019, 7, 8317-8330. 
(C) 2019 by the authors; licensee MDPI, Basel, Switzerland. This article is an open access article distributed under the terms and conditions of the Creative Commons Attribution (CC-BY) license (http://creativecommons.org/licenses/by/4.0/). 